\title{
Novas articulações da rede de cidades no Brasil: uma análise das heterarquias por meio do sistema de movimento aeroviário
}

\section{New articulations of the Brazilian cities network: an analysis of the heterarchies by the air flow system}

\author{
Sérgio Henrique de Oliveira Teixeira ${ }^{1}$ \\ Márcio José Catelan ${ }^{2}$
}

\begin{abstract}
Resumo
Diante da ordem global cada vez mais associada às redes de conexões, seus fluxos e suas relações com as cidades, os fixos articuladores nos fornecem elementos para novos entendimentos sobre a rede de cidades. No presente artigo temos como objetivo analisar a relação dos fluxos aéreos e a rede urbana brasileira, tomando como base os dados e as informações dos estudos sobre as regiões de influência das cidades (REGICs). Neste contexto é que lançamos mão da proposta teórico-metodológica sobre a Heterarquia Urbana, um complemento para entendermos as articulações multi e interescalares na rede urbana que explodem ao padrão hierárquico rígido. Neste sentido, o artigo foi estruturado em três focos analíticos: a) à análise do conteúdo da REGIC, mostrando os estudos anteriores e o detalhamento de sua metodologia atual; b) a definição do que compreendemos na relação hierarquia-heterarquia e c) análise do conteúdo espacial por meio do estudo empírico dos fluxos regionais do sistema de movimento aeroviário. A análise, portanto, mostrou mudanças na estruturação e nas articulações da rede de cidades: os fluxos do sistema de movimento aeroviário revelaram que ao mesmo tempo que há um reforço da hierarquia urbana, também há consolidação de relações complexas nas cidades médias, promovendo a heterarquia urbana.
\end{abstract}

Palavras-chave: Hierarquia-Heterarquia Urbanas. Fluxos Aéreos. Rede Urbana. Concentração Espacial. Sistema Aeroviário.

\begin{abstract}
Faced with the global order increasingly associated with the networks of connections, their flows and their relations with the cities, the fixed articulators provide elements for new understandings of the network of cities. In the present article, we aimed to analyze the relationship between air flows and the Brazilian urban network, based on data and information from the studies on the regions of influence of the cities (REGICs). In this context, we have used the theoretical-methodological proposal of Urban Heterarchy, a complement to understand the multi and interscalar articulations in the urban network that explode to the rigid hierarchical pattern. For that matter, the article is structured in three analytical
\end{abstract}

\footnotetext{
${ }^{1}$ Instituto Federal de Educação, Ciência e Tecnologia do Sul de Minas Gerais, Poços de Caldas, Minas Gerais, Brasil. sergio.teixeira@ifsuldeminas.edu.br

2 Universidade Estadual Paulista, Presidente Prudente, São Paulo, Brasil. marcio.catelan@unesp.br Recebido em: 28/05/2018. Aceito em: 04/10/2019.
} 
focuses: a) to the analysis of the REGIC content, showing the previous studies and the details of its current methodology; b) the definition of what we understand about the relation hierarchy-heterarchy and c) the analysis of the spatial content through the empirical study of the regional flows of the air movement system. The analysis, therefore, showed changes in the structuration and articulations of the network of cities: the flows of the air traffic movement system revealed that, at the same time that there is a reinforcement of the urban hierarchy, there is also a consolidation of the complex relations in the medium cities, promoting the urban heterarchy.

Keywords: Urban Hierarchy-Heterarchy. Airflow. Urban Network. Spatial Concentration. Airport System.

\section{Introdução}

As mudanças pelas quais a rede urbana brasileira passou advêm da complexidade de processos - urbanização, globalização, metropolização etc. dos quais novas funcionalidades surgiram, alterarando os padrões clássicos da rede, marcada pela estrutura hierárquica. Estes processos, especializados pela relação entre o movimento de concentração, desconcentração e reconcentração espacial, não nos permitem aceitar mais que a rede urbana possa ser vista em sua complexidade apenas pelo paradigma hierárquico, aquilo que Kosik (2002) chamou de "paradigma fragmentário da totalidade".

Ao compreendermos a rede urbana por meio do paradigma da fragmentação, construído na relação entre a totalidade e as partes, consolidamos o paradigma hierárquico que a tudo abarca. No que se refere à rede urbana e ao processo de urbanização, muitas vezes, o paradigma hierárquico nos impede de valorizar as articulações interescalares em detrimento de uma estruturação rígida da rede.

A rede urbana, compreendida a partir do paradigma fragmentário, resultou em análises sobre as interrelações entre as cidades com foco no padrão hierárquico, explicado pela concentração espacial do capital no território que ocorre de forma diferenciada. As empresas foram espacializadas mediante o processo de concentração seguido da desconcentração, sobretudo a partir de meados do século XX, quando a 
indústria paulista saiu da região metropolitana em direção ao centro-oeste do estado de São Paulo. Há também aquelas empresas já existentes em cidades de porte médio e cidades médias, ainda que pequenas e de pouca sofisticação no padrão organizacional, que ganham capacidade de produção beneficiadas pelo contexto regional e de articulação das lógicas no âmbito nacional e internacional.

Lencioni (2017) afirma que a concentração é o elemento supremo do desenvolvimento das metrópoles. Por nossa conta, poderíamos propor que a concentração seja o elemento supremo do desenvolvimento no âmbito da rede urbana, tendo em vista que este processo permite compreendermos a diferenciação espacial em densidade e rarefação (SANTOS, 1996). Sposito (2017) também contribui quando propõe o par concentração-extensão, pois, para a autora, devemos considerar as alterações nos papéis das cidades médias e pequenas no Brasil contemporâneo. No caso das primeiras, tem havido uma dimensão empírica da expansão das interações espaciais por meio de novas localizações de aeroportos no Brasil, conforme trabalharemos adiante.

Por isso é que o padrão hierárquico ainda é o mais visível ao olharmos a distribuição das empresas e do capital. Mas, exatamente por essa maior espessura e maior extensão da diferenciação no território é que vamos partir neste texto do par hierarquia-heterarquia trabalhado em IBGE (2017b), Sposito e Catelan (2015) e Catelan (2013) como a possibilidade de enxergarmos os interstícios da rede urbana via o movimento empreendido pelos fluxos aéreos.

Um novo padrão se conformou estabelecendo uma maior complementariedade de relações entre as cidades. Em uma mesma rede regional, novas funcionalidades dotam as cidades de relações hierárquicas de subordinação. Entretanto, com as mudanças operadas no capitalismo globalizado, vemos ascender nos últimos anos relações heterárquicas de complementariedades entre as cidades, rompendo as relações de 
subordinação clássicas. Por relações heterárquicas entendemos, conforme Catelan (2013), um conjunto de elementos que buscam identificar as articulações interescalares na rede urbana. É a horizontalidade articulada ao processo de concentração espacial na relação espaço-tempo do território brasileiro que nos permite olhar para as interações espaciais no âmbito do paradigma hierárquico, mas com novas qualidades dadas por interrelações da totalidade das escalas geográficas.

As redes de fluxos e seus aportes de fixos correspondentes estão entre as principais causas das articulações entre as cidades. Os fluxos dotam as cidades de novas funções, alterando seus papéis na rede urbana. O sistema de movimento aeroviário, por se tratar de uma das manifestações da rede urbana, é uma das causas dessas mudanças. Cidades que passam a contar com aeroportos mudam seus relacionamentos diante da hierarquia e da heterarquia e passam a ter importância cada vez maior dentro da rede. Procuramos analisar, neste trabalho, essas transformações ocorridas sobretudo a partir da década de 2000, momento em que as dotações de infraestruturas na rede urbana, com foco nas cidades médias, contribuíram para mudanças no padrão de estruturação da rede urbana. Isso é defendido por nós a partir da ideia de heterarquia urbana que põe luz sobre as articulações, principal hipótese a ser defendida ao longo do texto.

Contribuição das pesquisas sobre as regiões de influência de cidades para os estudos da geografia urbana brasileira: mudanças nos aspectos teóricometodológicos

Os estudos sobre a rede urbana brasileira, advindos do Instituto Brasileiro de Geografia e Estatística (IBGE) e do Instituto de Pesquisa Econômica Aplicada (IPEA) seguem uma tradição de cinco décadas, o que nos confere uma série histórica de pesquisas sobre o território nacional tendo como base as interações espaciais entre cidades e regiões. Durante esse longo período, os estudos acompanharam o desenvolvimento das 
cidades brasileiras e os referenciais teóricos sobre os estudos urbanos em seis (6) principais publicações: IBGE (1967); IBGE (1970); IBGE (1972); IBGE (1987); IBGE (2000) e IPEA (2002).

Os referenciais teóricos fundamentadores desses estudos se encontram nas leituras clássicas da rede urbana brasileira por meio da classificação estrutural dos centros urbanos (ROCHEFORT, 1961) e da teoria das localidades centrais (CHRISTALLER, 1966). Para Rochefort (1961), a rede urbana seria composta por relações de dependência e complementariedade entre as cidades polarizadoras na distribuição dos bens e serviços que dotam as mais densas cidades de maior centralidade. Entre essas cidades existem relações que são feitas em centros intermediários e que são também hierarquizadas, tendo em vista a distribuição de bens, serviços e fluxos que caracterizam a hierarquia urbana.

No quadro de uma região, a atividade de relação está, pois, garantida por toda uma hierarquia de cidades que mantêm, umas com as outras, relações de dependência. Daí não se pode mais estudar uma cidade isoladamente, como forma de atividade: a unidade deverá ser a rede urbana, definida dentro dos limites de influência de uma grande cidade, capital da região, pela existência e a localização de um certo número de tipos de cidades intermediárias - elas próprias hierarquizadas, que constituem as malhas da rede (ROCHEFORT, 1961 p.3).

Nessa concepção, a realização da rede urbana só é possível por conta das cidades intermediárias pelas quais se articulam os fluxos fundamentais para as grandes cidades. Rochefort (1961) chamou a atenção para essa articulação quando tomou como recorte analítico e empírico a estruturação das redes de transporte e comunicação. Para o autor, "A análise da organização dos transportes, causa parcial da hierarquização dos centros, e o estudo da repartição da rede telefônica, consequência dessa centralidade, tornaram-se, assim, métodos indiretos de investigação para definir os tipos de centro de uma rede urbana" (ROCHEFORT, 1961, p. 5). 
A metodologia dos centros polarizadores avança para a análise da importância dos transportes, valendo-se dos estudos de Christaller (1966), que buscam caracterizar as localidades centrais por meio das interações das ligações das redes para o consumo de bens e serviços instalados nas cidades. Segundo essa teoria, a frequência da demanda acarreta padrões de localização diferenciados: bens e serviços de consumo frequentes podem ser oferecidos por centros acessíveis a uma população próxima, têm mercado mínimo e alcance espacial reduzidos. Os bens e serviços de uso mais raro, por outro lado, têm mercado mínimo e alcance espacial maiores e tendem a localizar-se em um menor número de centros urbanos de hierarquia mais elevada.

As leituras da rede urbana feitas a partir dos princípios propostos por Rochefort e Christaller demonstraram a hierarquia dos centros urbanos determinada pela capacidade dos estabelecimentos comerciais e industriais, presentes em uma aglomeração urbana, de fornecerem bens e serviços a uma região de relativa distância do centro fornecedor, conferindo a esta sua polarização espacial.

Embora ainda vigente, o paradigma hierárquico não pode ser o único conjunto interpretativo de articulação das metodologias para se compreender as cidades e regiões. Recentemente, sobretudo desde o início dos anos 2010, diversos trabalhos (CATELAN, 2013; IBGE, 2017a; 2017b; SPOSITO; CATELAN, 2014; SPOSITO, 2017) sobre cidades médias vêm contribuindo com estudos sobre o Brasil urbano antes reconhecido por meio de metodologias e sistemas interpretativos gerados no âmbito das lógicas metropolitanas. Esses estudos vêm permitindo que se construa, como lembrou Sposito (2017), vários pontos de vista sobre o processo de urbanização e a rede urbana. Para a autora, o ponto de partida da análise da rede urbana deve levar em conta múltiplas interpretações, 
pesquisador compreendido como sujeito central no processo de condução da pesquisa, bases empíricas a partir das quais se elaboram leituras teóricas etc. (SPOSITO, 2017, p. 186).

De todos os aspectos levantados, cremos que a relação entre as conduções metodológicas e os fundamentos de método nos ajuda a qualificar e aproximar a ideia da heterarquia urbana defendida como par da hierarquia e modos de se compreender os novos arranjos do movimento no espaço via transporte aéreo. Isto porque, a heterarquia urbana é

[...] a possibilidade de compreensão dos interstícios gerados na estruturação hierárquica da rede urbana e na complexa trama de interações espaciais urbanas interescalares. No que se refere às cidades médias, a heterarquia urbana corresponde ao momento em que as horizontalidades e as verticalidades encontram-se, quando o local/regional é articulado definitivamente à reprodução do capital e às redes que passam a coexistir em múltiplas escalas. (CATELAN, 2013, p. 78).

Ao questionarmos o paradigma fragmentário, temos, então, duas formas complementares de se compreender as interações espaciais na rede urbana. Uma forma está associada diretamente à estrutura hierárquica da rede, ou seja, sua configuração e seu arranjo espacial com centros urbanos dispostos em níveis escalares de distintas funcionalidades. Outra forma está associada à complexidade das articulações entendidas pela heterarquia urbana, que analisa as interrelações de complementariedade na rede urbana por meio dos papéis e das funções que mudam conforme o conjunto de variáveis adotadas nas diferentes escalas geográficas.

Conforme Catelan (2013) e Sposito e Catelan (2015) temos, portanto, uma perspectiva hierárquica e outra heterárquica como forma de compreender a rede urbana brasileira, proposta como um par - hierarquia e heterarquia, para se entender a estruturação e as articulações da rede urbana nas múltiplas escalas. Essa ideia também foi adotada pelo IBGE (2017), por meio do estudo sobre a diferenciação socioeconômica em centros urbanos no Brasil, determinada pela concentração espacial cuja perspectiva 
do par Hierarquia-Heteraquia é assumida como forma de olharmos as articulações entre as cidades. Neste estudo, o Instituto Brasileiro de Geografia e Estatística avança na proposição colocada por Catelan (2013) e Sposito e Catelan (2015), ao trazerem a ideia de articulação por meio de um sistema urbano compreendido a partir do par, o que, para nós, reforça a análise com foco nos fluxos, no movimento espacial.

As múltiplas escalas que passam a interagir na rede urbana se manifestam na estrutura dos fluxos que se utilizam das redes intermediárias e conformam a heterarquia urbana da rede de cidades. A análise que se segue busca demonstrar as heterarquias recentes dadas pelas novas centralidades e reforço de algumas já consolidadas na rede urbana desde meados do século XX.

Novos elementos dos estudos contemporâneos da rede urbana: centros de gestão e heterarquia urbana

O estudo atual da região de influência de cidades buscou atualizar os estudos anteriores ao estabelecer a ideia de "redes hierárquicas e redes não hierárquicas definidas por suas relações de fluxos de comando e complementariedade”. Conforme as redes hierárquicas, a gestão - pública e empresarial - estabelece relações de controle e comando entre centros urbanos, "propagando decisões, definindo relações e destinando investimentos" (IBGE, 2008 p.9), características estas que levam à conformação dos centros de gestão do território (IBGE, 2014).

A partir da ideia de ligações hierárquicas, cria-se as classificações para a rede urbana estabelecidas pelos centros de gestão. Os centros de gestão do território (empresarial e/ou governamental) caracterizam-se como aquelas cidades onde se localiza uma grande diversidade de órgãos do Estado e sedes de empresas, a partir das quais são tomadas decisões que afetam direta ou indiretamente um dado espaço (CORRÊA, 2006) (Mapa 1). 
Mapa 1 - Brasil: Fluxos de gestão e comando no território, 2018.

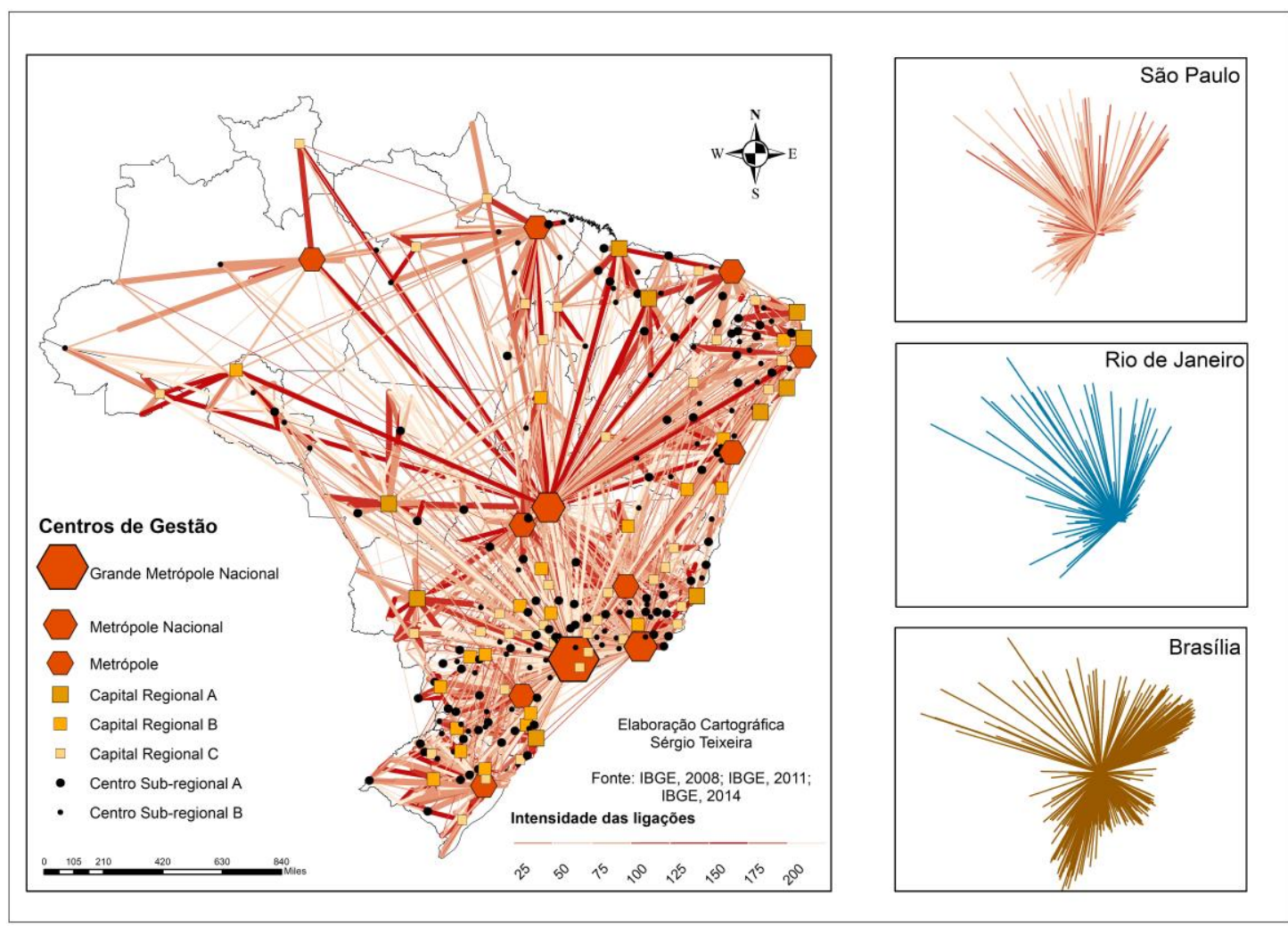

Fonte: IBGE, 2008; IBGE, 2011; IBGE, 2014. Org: Sérgio Teixeira, 2018.

As relações não hierárquicas, por sua vez, ocorrem nas cidades que mantêm relações de "complementaridade, que podem ser definidas pela especialização produtiva, pela divisão funcional de atividades e pela oferta diferencial de serviços" (REGIC, 2008, p. 9). Entretanto, "os arranjos dados de modos não hierárquicos, tanto entre centros urbanos como entre as redes, nos parecem menos claros, de maiores dificuldades para investigá-los" (CATELAN, 2013 p. 76). Daí partimos da ideia genérica do "não hierárquico" para denominá-la no escopo da heterarquia urbana.

Se já consideramos na seção anterior que é relevante olharmos para a concentração e a polarização espacial (IBGE, 2017), vale destacar aqui a relação no âmbito da concentração espacial entre os centros de produção e de gestão do capital, preponderantes para se analisar a distribuição dos fluxos no território brasileiro. Isto se deve ao fato de que os centros de gestão do 
capital, conforme estudos do IBGE (2008, 2014), também seguem o padrão da concentração advinda do papel assumido pelos grandes centros urbanos que envolvem metrópoles e regiões metropolitanas, como vemos no mapa 1.

Portanto, quando falamos, nesse período, em integração territorial, na verdade, estamos falando de interconexão de centros urbanos que polarizam e comandam o processo industrial. A rede urbana brasileira passa a ser comandada por centros de mais alto nível na hierarquia urbana, localizados nos centros industriais das regiões Sudeste e Centro-Oeste, em especial, nas cidades de São Paulo, Rio de Janeiro e Brasília, estabelecendo ligações de comando em todo o território (Mapa 1). A constituição de densas redes de telecomunicações e transporte possibilitou o aumento dos fluxos materiais, imateriais e de pessoas entre as cidades e regiões.

A especialização funcional na rede urbana ajuda a explicar o aparecimento de centros urbanos que assumem o papel de gestão intermediária do capital com escritórios empresariais articuladores da produção em múltiplas escalas. Esses escritórios de gestão são também articuladores da interescalaridade por serem responsáveis pela logística do comércio exterior, atuando como intermediadores a partir de metrópoles, capitais e centros de articulações regionais, conformando regiões intermediárias onde as heterarquias acontecem de forma mais densa (Mapa 2).

As Regiões Geográficas Intermediárias são uma forma de pensarmos o território articulado, detalhado pelas Regiões Geográficas Imediatas por meio de um polo de hierarquia superior diferenciado a partir dos fluxos de gestão privada e pública e da existência de funções urbanas de maior complexidade (IBGE, 2017) (Mapa 2). 
Mapa 2 - Brasil: Centros de gestão intermediários

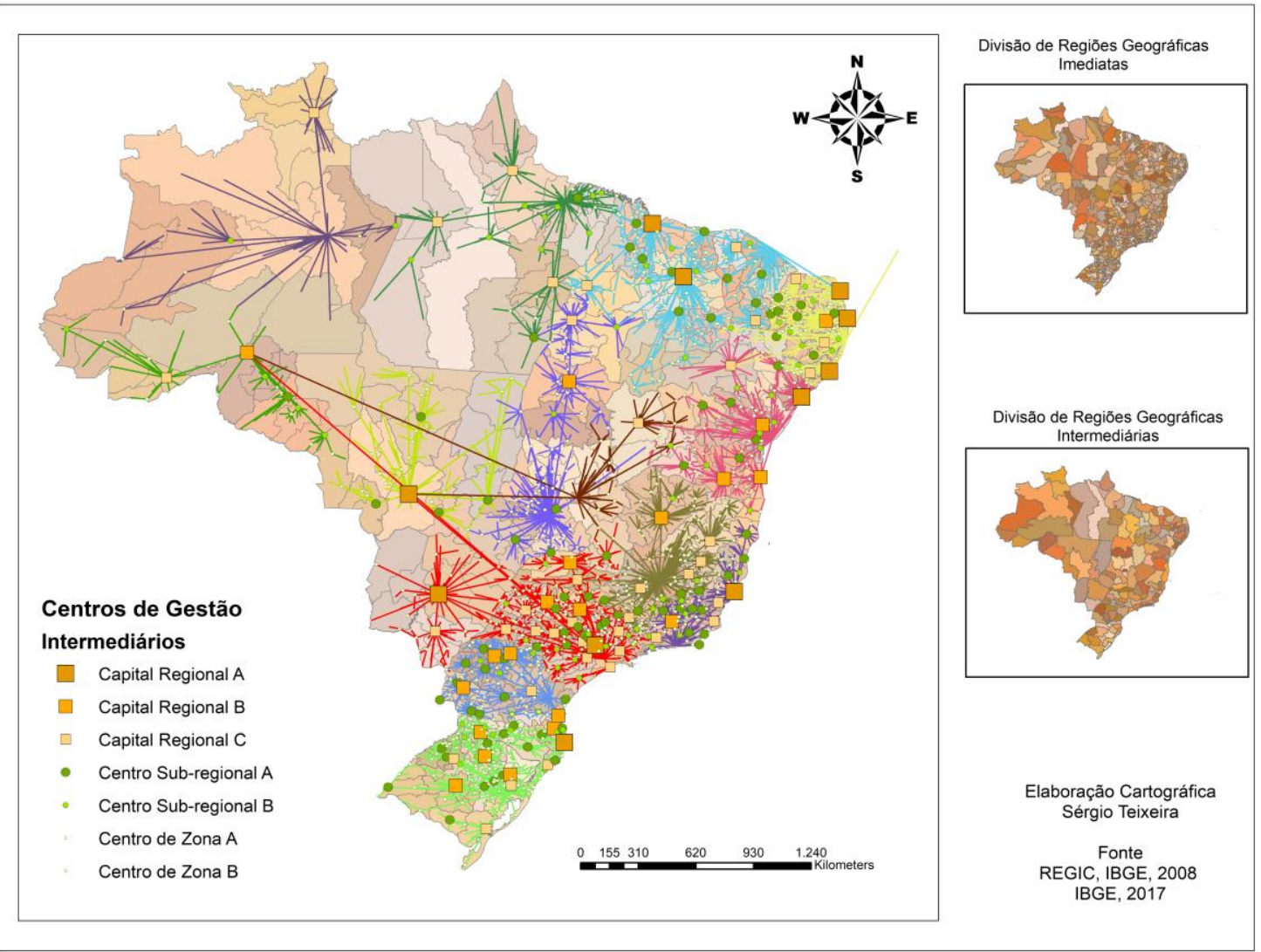

Fonte: IBGE, 2008; IBGE, 2017. Org: Autores, 2018

Os rebatimentos desta refuncionalização na rede urbana têm efeitos na distribuição dos aeroportos no Brasil e no reforço de que parte dela e, em especial, as cidades médias, seria a principal receptora destes equipamentos. Se no mapa da gestão e do comando no Brasil, vemos uma clara concentração espacial na região Sul/Sudeste e as metrópoles como São Paulo, Rio de Janeiro e Brasília como pontos desta concentração, por outro lado, há um movimento claro em direção às novas centralidades, como é o caso de cidades médias articuladoras das regiões geográficas intermediárias. Isto porque, muitas empresas apostam na fusão entre a produção e a gestão.

Percebemos claramente essa relação quando, ao analisarmos o mapa 2, fica evidente que os centros de gestão são hierarquicamente organizados a partir dos centros urbanos que são metrópoles, como também a partir de 
áreas de concentração populacionais (ACP) que abarcam um número considerável de cidades caracterizadas como capitais regionais. Nestas capitais regionais, muitas delas cidades médias, a gestão da produção não passa pelos centros de comando do capital, como as três metrópoles citadas no mapa 1. É nestas cidades que acontece a interescalaridade na lógica das empresas com saltos de escalas entre o local/regional e o global.

As cidades são articuladas entre si, compondo um sistema hierárquico e heterárquico (de complementariedade) de funções (SPOSITO; CATELAN, 2014). Desta forma, elas são hubs de uma ou mais redes de cidades que se articulam de modo a viabilizar o fluxo de mercadorias, informações e ordens (IBGE, 2017, p. 09).

Portanto, concentração espacial e especialização funcional da rede urbana são dimensões no plano analítico para se compreender o movimento de espacialização do sistema aeroviário no Brasil, tendo em vista que a implantação dos aeroportos e a densidade dos fluxos aéreos se sobrepõem ao mapa da diferenciação espacial e produtiva que revela o padrão heterárquico da rede urbana.

\section{Redes de cidades e fluxos territoriais do sistema de movimento aeroviário}

A rede de cidades brasileira é constituída por eixos de ligações funcionais entre os fixos e os fluxos, nos quais o transporte de mercadorias, pessoas e informações integra uma complexa organização espacial da produção no território. Os aeroportos conformam um sistema de engenharia que se ancora como fixo de grande relevância nas cidades, fortalecendo as relações hierárquicas e heterárquicas. Portanto, tanto a rede de cidades quanto a rede de aeroportos, por serem fixos determinados por seus fluxos, têm uma relação indissociável, pois ambos qualificam seus usos por meio de densidades técnicas que promovem e das quais são tributárias. Uma cidade pode perder ou ganhar primazia dentro da rede urbana devido ao aumento 
ou diminuição do fluxo de pessoas e mercadorias que chegam em um aeroporto nela instalado, assim como um aeroporto pode ganhar mais relevância de fluxo se a cidade na qual está instalado passar a desempenhar nova função dentro da rede. O jogo entre perdas e ganhos de papéis, aumento e diminuição dos fluxos é inclusive um aspecto forte em nossa análise, afinal isto dependerá de muitos fatores elementares e complementares no processo de concentração espacial nestes centros urbanos. Aqui, eles são lidos pela presença dos aeroportos e fluxos aéreos, mas podem ser apreendidos por meio de muitos outros recortes empíricos, como os investimentos em políticas públicas, implantação de política habitacional, incentivos fiscais à ampliação do parque industrial - estes com inserção de produção de tecnologia -, às empresas de comércio e consumo, aos equipamentos de educação superior e de saúde etc. Por esta complexa composição, aliás, é que propomos, seguindo o estudo do IBGE (2011), uma interpretação sobre a rede de cidades por meio de dados primários e secundários sobre as funcionalidades dos centros urbanos, tendo em vista os fluxos aeroviários que atravessam a rede.

O fato de uma cidade ser servida por um aeroporto caracteriza sua centralidade, pois o próprio estabelecimento de bens e serviços de uma infraestrutura de um fixo aeroportuário transmite à cidade quantidades variáveis de fluxos que conformam também um reposicionamento na hierarquia, consolidando um movimento complexo e heterárquico, uma nova condição na rede urbana. Em um contexto de crescente popularização da aviação comercial, as ligações aéreas representam um indicador do relacionamento entre os centros urbanos, propiciando, de maneira cada vez mais acessível, o transporte rápido a longas distâncias.

Os fluxos derivados do transporte aéreo fornecem, assim, uma geografia da estrutura da rede urbana, dado que constituem um instrumento de realização das interações espaciais entre as cidades, sobretudo no que diz respeito às funções de alto nível (gestão de empresas, 
sede de companhias, prestadores de serviços avançados, representantes do aparelho de Estado etc.) (IBGE, 2011, p. 08).

Constatamos que, a partir da década de 1990, novas centralidades ganham força em cidades médias, decorrentes da descentralização administrativa/federativa operada a partir da Constituição Federal de 1988. O processo de descentralização, no âmbito do pacto federativo, ampliou a participação da esfera municipal, sobretudo no que se refere à gestão dos impostos e fundos. Esta mudança fez com que algumas cidades ganhassem maior protagonismo, ampliando suas capacidades de articulação na rede urbana. Principalmente com foco em negócios corporativos, muitas empresas acabaram por romper as escalas e a hierarquia da rede urbana, estabelecendo relações diretamente com centros globais, atraindo cada vez mais negócios para as cidades médias e centros intermediários. Isso confirma que, além de verticalidades,

[...] as cidades, contudo, mantêm também relações horizontais, de complementariedade, que podem ser definidas pela especialização produtiva, pela divisão funcional de atividades, e pela oferta diferencial de serviços. Isso pode ocorrer, inclusive, entre centros de mesmas funções e papéis e em múltiplas escalas. (CATELAN, 2013, p. 76).

A complexidade do movimento aeroviário incita a valorização da perspectiva das heterarquias urbanas, sobretudo por meio das ligações aeroportuárias realizadas nas cidades médias a partir da segunda metade da década de 1970.

Do ponto de vista dos dados apresentados, esse período é muito relevante, posto que o Estado passa a fazer séries históricas de fluxos, nos possibilitando detalhar ainda mais as influências da instalação de aeroportos nas cidades, identificando suas decorrências para o planejamento e para a refuncionalização das cidades na rede urbana. Em destaque no mapa 3 mostramos a extensão da rede aeroportuária em quatro fases distintas que atestam seu crescimento e seu relacionamento com a rede 
urbana. Nota-se que, após a constituição, em 1980, da empresa de infraestrutura aeroportuária (INFRAERO), temos uma rede densamente articulada em todo o território nacional, mas, em especial, com capilaridade nos centros de gestão intermediários.

Mapa 3 - Brasil: Fluxo aéreo de passageiros (1980-2010)

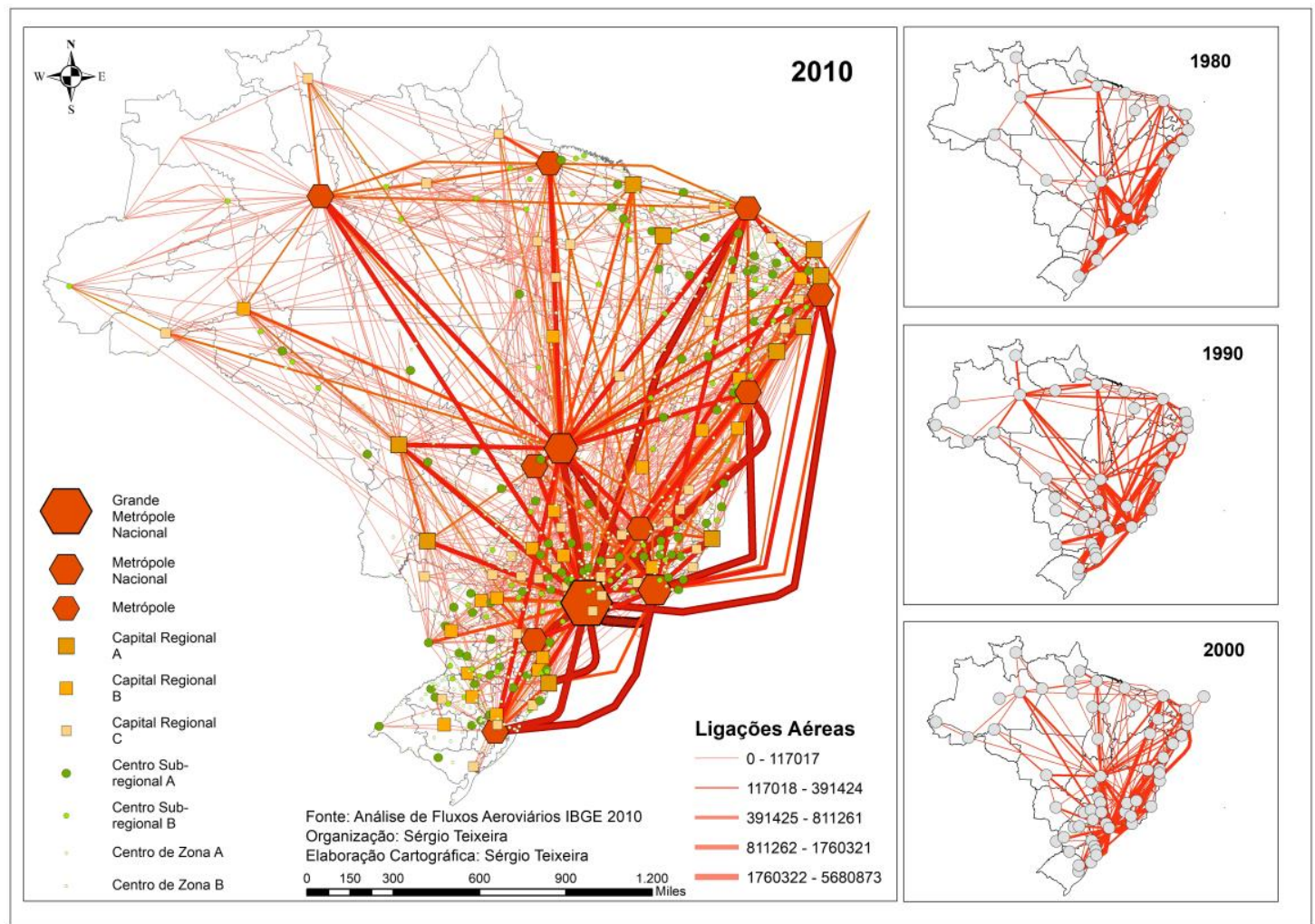

Fonte: IBGE, 2010. Org: Autores, 2018

Após a consolidação da INFRAERO como operadora do sistema de fluxos aeroviários, o número de cidades atendidas por aeroportos chegou a 23 no território nacional. As linhas de fluxos aéreos chegam a 66, distribuídas em todo o território nacional, com interligação direta entre os principais centros.

O destaque nessa nova rede são as ligações de Manaus/AM com outros centros urbanos depois de sua incorporação à rede nacional. A cidade deixou de manter sua principal conexão com Belém/PA e passou a estabelecer 
ligações diretas com São Paulo/SP desde que foi incorporada à rede da INFRAERO.

Outro destaque foi a inauguração do aeroporto de Brasília/DF, estabelecido como centro de distribuição da rede de aeroportos, se tornando o principal $h u b$ da rede aérea nacional. Além das mudanças proporcionadas pela dinâmica da rede urbana, houve uma enorme extensão dela, promovida por novas políticas para o setor. Rntre elas, se destacam os investimentos em ampliação da rede, decorrentes do Plano Nacional de Desenvolvimento I (1972-1974) e II (1975-1979). A política orientada por meio destes planos e o contexto político no qual estavam inseridos, o da Ditadura Militar, tinha um projeto de integração nacional articulado à proposta de desenvolvimento econômico. Isso se deu muito mais por meio de uma visão estratégica sobre o território brasileiro. Ao nosso ver, tal visão foi orientada pela desconcentração do Centro-Sul em direção à geração de concentração espacial em regiões a serem consolidadas como norte e nordeste para fins de controle do território, com investimentos direcionados a áreas como o transporte e outras que dependeriam dele para serem territorializadas no país.

Mesmo com a diminuição na implantação das obras ao final do regime militar, contexto do PND II, a integração territorial e o fortalecimento do mercado nacional durante o PND I criaram condições para a inserção da dinâmica produtiva brasileira no mercado internacional. Logrado certo êxito em absorver os investimentos externos, a industrialização possibilitou a entrada, ainda que lenta, do Brasil no mercado internacional, aumentando a participação dos bens manufaturados no mercado externo e promovendo o aumento dos fluxos no território.

A organização do espaço e o padrão urbano-regional, decorrentes da integração do mercado nacional, tiveram profundas mudanças durante as décadas de 1960 e 1970. A integração territorial, comandada pela iniciativa de capitais externos, promoveu investimentos privados e públicos em pontos 
específicos no território, proporcionando uma organização espacial interligada, porém altamente hierarquizada entre centros urbanos industriais mais dinâmicos do território. Podemos aqui, segundo a definição clássica dos estudos regionais e geográficos, falar na constituição de uma rede de cidades altamente polarizada (CORRÊEA, 2006).

A próxima fase a ser analisada trata das transformações decorrentes da inserção competitiva da economia nacional no mercado externo no pós1980. Bresser-Pereira (2015) considera que, a partir de 1978, o "Ciclo Nação e Desenvolvimento", é o momento no qual o Brasil logrou a "Revolução Capitalista Brasileira”. A partir de 1980, o padrão de diversificação produtiva na pauta exportadora da indústria brasileira é interrompido pela crise da dívida externa advinda do período do "milagre econômico", assim chamado pela retomada dos investimentos durante a aplicação do Plano Estratégico de desenvolvimento (1968-1970) e durante os PNDs. No período dos PNDs, a dívida externa gerada girava em torno de 14,9 milhões de dólares, chegando a 55,8 em 1979, ao passo que o Produto Interno Bruto varia de 14 milhões de dólares em 1973 para 6,8 em 1979 (MATOS, 2002; IPEA, 2002). Os investimentos aplicados nas estruturas produtivas nacionais são drenados para o exterior, colocando a articulação do mercado interno em dificuldades. Ao mesmo passo, a economia mundial passa pelos ajustes da época neoliberal e da reestruturação produtiva que tiveram como mote um maior adensamento da inserção de frações dos territórios periféricos à economia mundializada, criando novas articulações dos espaços subnacionais com o mercado externo.

A desconcentração produtiva de São Paulo e da região Sudeste abre novas áreas que apresentam potenciais dinamizadores e áreas antigas (re)funcionalizadas, que passam a se conectar diretamente com o mercado externo, colocando ainda mais dificuldades para a organização do desenvolvimento de um mercado interno e preconizando partes do território à lógica da acumulação capitalista globalizada. 
De forma extremamente contrastante, o período pós-1980 foi caracterizado por surtos setorializados, incoerentes, instáveis e focalizados de crescimento econômico em restritos pontos do espaço em cada uma das macrorregiões brasileiras. A perda generalizada de dinamismo econômico e o alargamento dos desníveis socioeconômicos entre suas regiões foram determinados pelo ambiente macroeconômico internacional, as opções equivocadas de política econômica e a perda da qualidade sistêmica e orgânica da atuação do Estado, o que resultou em disritmias entre os investimentos públicos e privados. (BRANDÃO, 2011, p. 20).

Novas áreas e cidades recebem indústrias e capitais saídos da tradicional área core, região Sudeste do país com alta concentração na cidade e no estado de São Paulo, formando novos centros urbanos e fronteiras de expansão. As decorrências desse processo para a organização espacial do território marcam um novo padrão urbano-regional e de formação da rede urbana, caracterizada por uma maior fragmentação territorial, seguida de maior articulação das interações espaciais.

A desconcentração industrial da cidade de São Paulo para outras regiões alavanca um processo de desconcentração demográfica, complexificando a rede urbana com o surgimento de novas centralidades regionais (LENCIONI, 2011). Ao mesmo tempo, muitos núcleos urbanos passam a se articular diretamente com centros de decisão fora do território nacional, tornando-se polos independentes da rede, atrelados mais ao mercado internacional do que ao mercado interno. São os casos, principalmente, de cidades ligadas às atividades exportadoras mais dinâmicas, como o agronegócio e os bens industriais intermediários ou de centralidades de comando ligados aos serviços financeiros e de informação que conformarão novas heterarquias urbanas.

Em relação ao sistema de movimento aeroviário, há uma extensão das articulações dos aeroportos com esses novos centros urbanos que passam a requerer equipamentos aeroviários como forma de dinamizar seus fluxos e interações na rede, observando o período de 1990. 
O número de cidades servidas por aeroportos aumenta em baixa proporção, porém as linhas de fluxos acrescem em mais de 50\%. Enquanto, em 1990 havia 42 cidades com aeroportos, em 2000 há 60. Entretanto, enquanto, em 1990, havia um total de 104 linhas de fluxos aeroviários entre as cidades, em 2000, têm-se um total de 163.

Uma questão relevante deve ser considerada para o tema desse artigo. Enquanto a década de 1990 significou, no plano mais geral, a política de privatizações e cada vez mais autonomia para as cidades realizarem seus diversos tipos de planejamentos empresariais com a influência do capital internacional, no sistema aeroviário houve investimento estatal. Isso ocorreu devido às infraestruturas de fixos e fluxos territoriais serem demasiadamente onerosas para os capitais que solicitam sua aplicação por meio do Estado. Não à toa, na década seguinte, o número de aeroportos e investimentos estatais no setor aumenta de forma exponencial (TEIXEIRA, 2018).

Porém, devemos observar que, apesar de grande autonomia, a rede urbana é influenciada pelo planejamento territorial exercido na escala da formação socioespacial. Dessa maneira, a dotação de recursos da escala federal provoca uma grande disputa entre as cidades, o que levou Santos e Silveira (2001) e Rolnik (2015) a identificar uma verdadeira "guerra dos lugares", metáfora que expressa um número considerável de diferentes cidades em disputa por infraestruturas territoriais para abarcarem escritórios e plantas industriais de grandes corporações. É o caso dos recursos provenientes do Programa de Aceleração do Crescimento (PAC) criado em 2003.

A partir dos investimentos em Infraestruturas, destinados do PAC, para o sistema de movimento aeroviário observamos um crescimento vertiginoso das ligações de fluxos aéreos entre as cidades (mapa 3). Passamos de um total de 60 cidades servidas com aeroportos em 2000 para 149 em 2010, ou seja, um aumento de quase 200\% em uma década. Na 
mesma década, o número de ligações de fluxos salta de 163 linhas para 879, atestando um aumento de mais de 500\% (IBGE, 2011).

Ao observar os mapas, notamos a presença da heterarquia urbana expressa em novas centralidades alçadas por meio de novos fluxos que dotam as cidades médias de maiores interações interescalares. Estas ultrapassam a hierarquia dos centros de gestão do território de maior nível hierárquico, o que confirma a ideia de Santos (1996) quando o autor chama de "superposição de ações de diversas escalas". Para o autor,

\footnotetext{
Vários pontos distantes são, ao mesmo tempo, atingidos, a partir de um mesmo centro decisório que envia suas mensagens e ordens com eficácia. Ao mesmo tempo, a possibilidade atual de mundialização de um grande número de ações acarreta, para muitos lugares, o problema da superposição, neles, de ações com escalas diversas, portadoras de contextos com diversa abrangência geográfica e força ativa (ou reativa) diversa (SANTOS, 1996, p. 149).
}

Destaca-se, nessas articulações globais, o papel das cidades médias. Estas tornam-se portadoras de maiores fluxos, aumentando o número de cidades que se conformam como centros de importância na rede urbana, quanto sua influência na rede regional, promovendo mais interações territoriais e espaciais. Essas cidades alimentadas por quantidades maiores de fluxos se tornam pontos estratégicos às lógicas corporativas extravertidas globalmente. Além disso, no momento atual, elas próprias geram agentes econômicos hegemônicos no que se refere às dinâmicas e lógicas de sua produção e da consolidação de seus papéis. Isso porque agora elas não somente são atingidas, mas também promovem diferenciação socioespacial. Este é um fundamento da heterarquia urbana que ainda pretendemos explorar: a urbanização do território brasileiro é cada vez mais uma resultante da articulação escalar, portanto, a hierarquia urbana se consolida não somente pela estruturação rígida e clássica, como também por articulações complexas de saltos escalares e direções multivetoriais. Os 
fluxos aéreos, muito embora sejam organizados a partir de centralidades já consolidadas, também promovem consolidação de outras ainda em formação.

\section{Considerações finais}

Analisando as alterações do sistema aeroviário, percebemos que a estruturação das redes de fluxos e de aeroportos mantiveram o padrão de densidade e fragmentação da rede de cidades. Ao mesmo tempo, o sistema se ampliou estabelecendo novas densidades relativas à heterarquia urbana. Isto se deve, como destacado neste artigo, à relação indissociável entre as redes técnicas do sistema aeroviário e às mudanças pelas quais a rede de cidades vem passando nas múltiplas escalas.

A análise dos fluxos aeroviários na rede urbana mostra que ainda se verifica um padrão de concentração nas metrópoles litorâneas, na região Sudeste do país e na cidade de São Paulo, atestando a permanência da densidade técnica na região concentrada do território. Entretanto, novas centralidades surgem na rede, com destaque para as cidades médias que vêm compondo aglomerações urbanas conformadas pelas interações espaciais com as cidades locais e suas áreas de influências e, alguns casos, também com cidades de mesmas funções. É o caso das cidades médias que receberam investimentos de capital, sobretudo, a partir da década de 1970, com o processo de desconcentração industrial irradiado da metrópole paulista, ao mesmo tempo que geraram nelas ações de agentes políticos e econômicos que se incorporaram nas lógicas de reprodução do capital em múltiplas escalas.

Este processo se consolida na década de 1990, com a intensificação da guerra dos lugares, legitimada tanto no plano político-administrativo quanto na aprovação do pacto federativo na Constituição Federal de 1988, bem como no plano econômico, com a abertura do território à globalização. Decorre destes dois planos uma maior complexidade na estrutura 
hierárquica na rede urbana, tendo em vista que cidades fora das regiões metropolitanas, comandadas por metrópoles, como é o caso das cidades médias e de porte médio, explodem suas interações espaciais promovendo a heterarquia urbana.

A partir dos anos 2000, com os investimentos em infraestruturas decorrentes do PAC, as cidades médias tiveram a implementação de infraestruturas de circulação que dotaram essas cidades de maior centralidade, com reafirmação de seus papéis regionais, ao passo que nelas foram sendo implantados novos sistemas de infraestrutura e equipamentos regionais, como é caso dos aeroportos. Daí considerarmos estas relações com aspectos de interações funcionais num padrão de complexidade compreendida no escopo da heterarquia urbana.

\section{Referências}

BRANDÃO, C. A busca da utopia do planejamento regional. Revista paranaense de desenvolvimento, n. 120, p. 17-37, 2011.

BRESSER-PEREIRA, L. C. A construção política do Brasil: sociedade, economia e Estado desde a Independência. São Paulo: Editora 34, 2015.

CATELAN, M. J. Heterarquia urbana: interações espaciais interescalares e cidades médias. São Paulo: Cultura Acadêmica, 2013.

CHRISTALLER, W. Central Places in Southern Germany. Prentice-Hall: Inc. Englewood Cliffs, 1966.

CORRÊA, R. L. As redes de localidades centrais nos países subdesenvolvidos. Revista Brasileira de Geografia, p. 61-83, 1988.

GÓES, E. M. Cotidiano, consumo e vida urbana em cidades médias brasileiras, Confins, 28, 2016. https://doi.org/10.4000/confins. 11128

Estudo sobre a rede urbana. Rio de Janeiro: Bertrand Brasil, 2006.

IBGE. Instituto Brasileiro de Geografia e Estatística. Esboço preliminar da divisão do Brasil em espaços homogêneos e espaços polarizados. 3 vols. Rio de Janeiro: IBGE, 1967.

Divisão do Brasil em micro-regiões homogêneas. Rio de Janeiro: IBGE, 1968.

—. Divisão do Brasil em regiões funcionais urbanas. Rio de Janeiro: IBGE, 1972.

—. Regiões de influência de cidades. Rio de Janeiro: IBGE, 1987.

—. Regiões de influência de cidades. Rio de Janeiro: IBGE, 1993.

- Regiões de influência de cidades. Rio de Janeiro: IBGE, 2000.

_. Regiões de influência de cidades. Rio de Janeiro: IBGE, 2008.

—. Redes e fluxos no território: Ligações aéreas 2010. Estudo, Rio de Janeiro: IBGE, 2011.

_. Redes e fluxos no território: gestão do território 2014. Estudo de fluxos, Rio de Janeiro: IBGE, 2014.

Divisão regional do Brasil em regiões geográficas imediatas e regiões geográficas intermediárias: 2017, Rio de Janeiro: IBGE, 2017a. 
_. Tipologia intraurbano. Espaços de diferenciação socioeconômica nas concentrações urbanas do Brasil. Rio de Janeiro: IBGE, 2017b.

IPEA. Caracterização e Tendências da Rede Urbana do Brasil. Brasília: IPEA, 2002. KOSIK, K. Dialética do Concreto. Rio de Janeiro, 1976.

LAFER, B. M. Planejamento no Brasil. São Paulo: Editora Perspectiva. 1984.

LENCIONI, S. A metamorfose de São Paulo: o anúncio de um novo mundo de aglomerações difusas. Revista Paranaense de Desenvolvimento, Curitiba, n.120, p.133-148, jan./jun. 2011.

. Metropolização no Brasil. In: Suertegaray, Dirce Maria Antunes et al. Geografia e conjuntura brasileira. Rio de Janeiro: Editora Consequência, p. 185-2012, 2017. 2017.

Metrópole, metropolização e Regionalização. São Paulo: Editora Consequência,

MATOS, P. O. Análise dos planos de desenvolvimento elaborados no Brasil após o II PND. 184f. Dissertação (Mestrado). Universidade de São Paulo, São Paulo, 2002.

MELAZZO, E. S. Estratégias Fundiárias e Dinâmicas Imobiliárias do Capital Financeirizado no Brasil. Mercator, Fortaleza, v.12, número especial (2)., p. 29-40, set. 2013. https://doi.org/10.4215/RM2013.1202.0002

ROCHEFORT, M. Métodos de estudos das redes urbanas: interesse da análise e do setor terciário da população ativa. Boletim Geográfico, 160 ed.: p. 03-59. Jan./Fev., 1961.

ROLNIK, R. Guerra dos Lugares. São Paulo: Boitempo, 2015.

SANTOS, M. A natureza do espaço. São Paulo: Hucitec, 1996.

Técnica, espaço, tempo. São Paulo: Edusp, 2008.

SANTOS, M.; SILVEIRA, M. L. O Brasil: território e sociedade no século XXI. Rio de Janeiro: Record, 2001

SPOSITO, M. E. B.; CATELAN, M. J. Hierarchy and Heterarchy in Brazil's urban network. Brazilian Geographical Journal: Geosciences and Humanities research medium, Ituiutaba, v.5, n.2, pp. 556-554, jul/dec. 2014.

SPOSITO, M. E. B. Olhando de vários pontos de vista o processo de urbanização e a rede urbana. In: SUERTEGARAY, D. M. A. et al. Geografia e conjuntura brasileira. Rio de Janeiro: Editora Consequência, p. 185-2012, 2017.

TEIXEIRA, S. H. O. Planejamento corporativo e concessão aeroportuária no Brasil. Mercator, v.17 p. 1-15, 2018. https://doi.org/10.4215/rm2018.e17002 